\title{
Editorial
}

\section{Biochemia Medica indexed in PubMed Central (PMC)}

Ana-Maria Simundic

Editor-in-chief, Biochemia Medica, Zagreb, Croatia

As announced in the last journal issue (1), with great pleasure we wish to inform you that Biochemia Medica has just been accepted for indexing in PubMed Central (PMC) journal database (http:// www.ncbi.nlm.nih.gov/pmc/). All articles starting from 2012;22(3) are now available as free PMC articles and can be accessed directly at PMC. Free full PMC articles can also be accessed through link from PubMed.

The first ever Croatian journal accepted for indexing in PubMed Central was Croatian Medical Journal. Biochemia Medica is the second journal from Croatia that appears in PMC. It is a dream for many society journal editors. This is certainly an important milestone in our pursuit to join the competitive world of the mainstream science biomedical journals. We hope that through PMC, our journal

\section{References}

1. Huh S. ScienceCentral: open access full-text archive of scientific journals based on Journal Article Tag Suite regardless of their languages. Biochem Med 2013;23:235-6. http:// dx.doi.org/10.11613/BM.2013.029.

2. Simundic AM. Editing a scientific journal in Croatia: the case of Biochemia Medica. Eur Sci Edit 2012;38:69. will become more visible and accessible to much wider research community.

PMC is a free full-text archive of biomedical and life sciences journal literature at the U.S. National Institutes of Health's National Library of Medicine (NIH/NLM). Currently, almost 3 million articles are archived in PMC, provided by more than 4,000 Journals. We are proud to be one of them! Such recognition is a result of a hard work of our editorial team who is determined to maintain and continuously improve the journal quality, by adhering to highest quality standards (2).

Editors at Biochemia Medica wish to thank to all our authors and reviewers for their continuous contribution to the success of our journal. We also wish to thank to our readers for their valuable feedback. 